\title{
Cultivar Mixtures for the Simultaneous Management of Multiple Diseases: Tan Spot and Leaf Rust of Wheat
}

\author{
C. M. Cox, K. A. Garrett, R. L. Bowden, A. K. Fritz, S. P. Dendy, and W. F. Heer
}

First, second, and fifth authors: Department of Plant Pathology; third author: U.S. Department of Agriculture-Agricultural Research Service; and fourth and sixth authors: Department of Agronomy, Kansas State University, Throckmorton Hall, Manhattan 66506. Accepted for publication 30 April 2004.

ABSTRACT

\begin{abstract}
Cox, C. M., Garrett, K. A., Bowden, R. L., Fritz, A. K., Dendy, S. P., and Heer, W. F. 2004. Cultivar mixtures for the simultaneous management of multiple diseases: Tan spot and leaf rust of wheat. Phytopathology 94:961-969.

Because of differences in life histories between Puccinia triticina, a highly specialized, polycyclic, windborne pathogen with a shallow dispersal gradient, and Pyrenophora tritici-repentis, a residue-borne pathogen with a steep dispersal gradient, wheat mixtures are expected to be more effective at controlling leaf rust than tan spot. The objectives of this research were to determine the effect of two-cultivar mixtures with varying proportions and different pathogen resistance profiles on the severity of tan spot and leaf rust, to evaluate yield of the mixtures in the presence or absence of disease, and to directly compare the relative effectiveness of cultivar mixing for tan spot versus leaf rust. In a field experiment at two sites in Kansas over two growing seasons, winter wheat cvs. Jagger and
\end{abstract}

2145, which have differential resistance reactions to leaf rust and tan spot, each were planted in proportions of $0.25,0.50,0.75$, and 1.00 . Plots were inoculated with each pathogen alone, both pathogens, treated with a fungicide, or exposed to ambient conditions. For both diseases for all siteyears, severity decreased substantially on the susceptible cultivar as the proportion of that cultivar decreased in mixture. Mixtures were significantly more effective at reducing leaf rust than tan spot in three of four site-years. Mixtures generally yielded the same as the weighted mean of components in monoculture although, in two of three site-years, at least one fungicide-treated and one diseased mixture each yielded higher than expected values. Although this particular mixture produced only modest yield benefits, the potential for simultaneous reductions in tan spot and leaf rust was demonstrated.

Additional keywords: blends, frequency-dependent effects, host diversity, plant diversity, polyculture, variety mixture.
The practice of growing crops in homogenous monocultures contributes to severe disease epidemics in agriculture (6). The ability of small-grain cultivar mixtures to substantially reduce the severity of polycyclic, specialized, wind-dispersed foliar diseases, such as rusts, powdery mildews, and rice blast, has been well demonstrated $(5,6,26,27,32,45,47)$. Fewer studies, however, have examined the effects of mixtures on soilborne, monocyclic, or splash-dispersed diseases and the results of these empirical studies have been less consistent $(9,19,20,31-33,43)$. Evaluating multiple diseases in a single experiment allows both a direct comparison of mixture efficacy for different disease types and the opportunity to consider the possibilities for mixtures to simultaneously manage multiple diseases.

Mixture efficacy is greater under certain epidemiological conditions than others. Garrett and Mundt (14) suggest that the effects of host diversity will tend to be greatest when the host genotype unit area is small, there is strong host specialization, the pathogen's dispersal gradient is shallow, characteristic lesion sizes are small, and the number of pathogen generations is large. Diseases caused by wind-dispersed pathogens often are more effectively reduced in mixtures than those caused by splashed-dispersed pathogens, probably due to the shallower dispersal gradients of the former. A shallower dispersal gradient tends to result in more movement of propagules away from the susceptible host, provided that an influx of inoculum does not saturate a field (14). In light of these assumptions, cultivar mixtures would be ex-

Corresponding author: K. A. Garrett; E-mail address: kgarrett@ksu.edu

Publication no. P-2004-0714-03R

(c) 2004 The American Phytopathological Society pected to have less effect (over one growing season) on diseases that are monocyclic, splash dispersed, or soilborne.

A limited number of studies have addressed the effects of host diversity on such diseases. Vilich-Meller (43) observed substantially reduced severity of eyespot (caused by Tapesia yallundae (anamorph Pseudocercosporella herpotrichoides)), Rhizoctonia cerealis stem rot, and Fusarium spp. in mixtures of different cereal species in Germany. Other studies have demonstrated similar mixture effects for root and soilborne diseases, including crown and root rot of sugar beet caused by Rhizoctonia solani (19), and soilborne wheat mosaic, a viral disease with a soilborne vector (20). Substantial yield increases in mixtures compared with monocultures have occurred in on-farm trials for wheat mixtures infected with Cephalosporium gramineum (31), despite the ineffectiveness of the mixtures at reducing severity of Cephalosporium stripe. Mundt et al. (33) observed significantly reduced eyespot severity in only three of seven wheat mixture populations and only in the absence of stripe rust. The ability of wheat mixtures to suppress Mycosphaerella graminicola, the causal agent of Septoria tritici blotch, in a 3-year field study was inconsistent (9). The mechanisms for reductions of residue-borne and soilborne diseases in mixtures are not well understood $(32,33)$. Environmental conduciveness for disease development and secondary spread of the pathogen may be key factors determining the effectiveness of mixtures in such pathosystems.

Researchers studying the use of mixtures typically consider genotypes that differ in their level or type of resistance to a single disease, but combinations of genotypes also may be selected that differ in their resistance to multiple diseases. When resistance to all relevant diseases cannot be obtained in a single desirable cultivar, combining cultivars in a mixture may be a useful strategy for disease management. For example, the wheat cv. Jagger has been 
popular in the Great Plains region of the United States, but has demonstrated decreasing resistance to prevalent leaf rust races (R. Bowden, unpublished data). The new cv. 2145 has many desirable traits for adaptation to the Great Plains, including resistance to leaf rust, but lacks tan spot resistance. By mixing these two cultivars with differential disease resistance (one cultivar is resistant to one disease while the other cultivar is resistant to another disease), it may be possible to manage both diseases simultaneously.

Although it may be possible to predict how effectively mixtures will slow disease epidemics for pathogens with different life histories (14), there have been very few direct experimental comparisons. Mitchell et al. (29) estimated the effects of different diversity levels on several host-pathogen combinations in a perennial prairie plant community, though comparisons between host-pathogen systems in this study are complicated by lack of information about when pathogens were introduced to the experiment. Mundt et al. (33) examined disease severity and yield in wheat mixtures inoculated simultaneously with stripe rust and eyespot; few of the mixtures were differential in terms of resistance to these two diseases and the relative effectiveness of mixtures for one disease versus the other was not analyzed directly. In a greenhouse study, Lannou et al. (23) considered the relative effectiveness of mixtures for two wheat rust diseases that differed in lesion size and found that mixtures were more effective at reducing levels of disease with small lesion size (leaf rust) relative to disease with large lesion size (stripe rust) due to rapid host saturation by the latter. Mixture effectiveness in the presence of both diseases was not examined and the mixtures studied were not designed to function in multiple disease management.

Tan spot, caused by the fungus Pyrenophora tritici-repentis, is an important residue-borne foliar disease on wheat and other gramineous hosts, including barley, oat, rye, and various wild grasses $(21,44)$. Increased severity of tan spot is associated with reduced tillage and continuous wheat systems (2,3,22,37). Ascospores are formed on surface crop residue and splash-dispersed to the growing crop in the spring. Conidia are formed from lesions on infected leaves and dispersed by wind, initiating the secondary cycle. The secondary infection cycle is considered the most significant in terms of crop losses (38), though the number of generations of tan spot produced under field conditions is believed to be small compared with leaf rust. As is characteristic of many residue-borne and soilborne pathogens, the number of generations of $P$. tritici-repentis generally is low during a growing season and its dispersal gradient is steep (41). In contrast, Puccinia triticina, the causal agent of leaf rust, is typical of many windborne pathogens in that it is highly specialized, polycyclic, and follows a shallow dispersal gradient (10).

Because of these life history differences and based on Garrett and Mundt's (14) arguments, one would predict that the severity of tan spot would be less affected in mixtures than leaf rust. Wheat mixtures have been shown to significantly slow leaf rust progression (26), but the effects on tan spot are unknown. Direct comparisons of mixture efficacy on multiple diseases caused by pathogens with different life history characteristics, on the same temporal and spatial scales, would provide greater understanding of mechanisms for management of multiple diseases and improve predictability for mixture effectiveness of reduced disease based on characteristics of the host, pathogen, disease cycle, and environment.

If mixing wheat cultivars proves successful at simultaneously managing both residue- and windborne pathogens, there would be few obstacles to adopting such a practice at the farm level. In Kansas, mixtures consisting of two to three different cultivars covered $7 \%$ of the wheat acreage in $2001,11.5 \%$ in 2002 , and $12.8 \%$ in 2003, according to the Kansas Agricultural Statistics Service. Farmers initiated this practice primarily because the popular and high-yielding cv. Jagger lacks strong winter hardiness. Mixing Jagger with a lower-yielding but more winter-hardy cultivar reduces the risk of crop failure and increases yield stability over time (4). The cultivars used in this study, Jagger and 2145, which have differential resistance levels to tan spot and leaf rust, potentially could be useful in mixture for reducing disease in the Great Plains.

The objectives of this research were to (i) determine the effect of wheat cultivar mixtures with differential levels of resistance on severity of tan spot and leaf rust, (ii) directly compare the relative effectiveness of cultivar mixing for tan spot versus leaf rust, and (iii) evaluate yield of the mixtures in the presence and absence of these diseases.

\section{MATERIALS AND METHODS}

Field plots. The experiment was conducted at Kansas State University experimental farms in Manhattan and Hutchinson, KS, during the 2000-01 and 2001-02 growing seasons. Manhattan lies in the Flinthills of northeastern Kansas and Hutchinson is in south-central Kansas; both locations receive, on average, 930 to $940 \mathrm{~mm}$ of precipitation annually. Wheat planting took place during the first week of October and harvesting the last week in June at both sites in both years.

Two hard red winter wheat cultivars, Jagger and 2145, each were planted in proportions of $0.25,0.50,0.75$, and 1.00. Jagger is moderately resistant to tan spot and susceptible to leaf rust, and 2145 is resistant to leaf rust and susceptible to tan spot. Jagger can be visually distinguished from 2145 beginning shortly after heading by head color: Jagger has brown chaff and 2145 has white chaff and is waxy blue before maturity. The different genotype proportions were combined in a factorial design with each of five disease treatments: tan spot inoculated alone, leaf rust inoculated alone, tan spot plus leaf rust inoculated, fungicide application, and ambient conditions. Each plot consisted of six rows in an area of 1.5 by $4.6 \mathrm{~m}$ and was separated from other plots by $1.5-\mathrm{m}$ borders of triticale cv. Presto on all sides. Presto is highly resistant to both diseases. The 25 treatment combinations were randomized in five complete blocks. One replication was abandoned at Hutchinson in the second field season due to a planting error.

Wheat and triticale seed were planted at a rate of $108 \mathrm{~kg} / \mathrm{ha}$. Prior to planting in both years of the experiment, nitrogen fertilizer was applied to field sites at $56 \mathrm{~kg} / \mathrm{ha}$ and an additional application of top dress at $56 \mathrm{~kg} / \mathrm{ha}$ was made in the spring just before wheat plants jointed. Fungicide plots were treated twice in the spring beginning the first week of May, and again 2 to 3 weeks later with Tilt $3.6 \mathrm{E}$ fungicide at $0.29 \mathrm{liter} / \mathrm{ha}$ in a total spray volume of 234 liter/ha using Teejet 8002 flat fan nozzles running at $0.207 \mathrm{MPa}$ on $380-\mathrm{mm}$ spacing.

Fungal inoculum and disease establishment: Pyrenophora tritici-repentis. Inoculation procedures were based on methods described by Raymond et al. (36). Four different isolates of Pyrenophora tritici-repentis collected in Kansas were grown on quarter-strength potato dextrose agar in petri dishes for approximately 1 week in the light at room temperature. Squares of agar $\left(\approx 2.5 \mathrm{~cm}^{2}\right)$ were sliced from cultures with a sterile scalpel and submerged into sterilized oat kernels in glass jars (140 g of kernels in $150 \mathrm{ml}$ of water). After the fungus had spread through an area $\approx 8 \mathrm{~cm}$ in diameter, jars where shaken every 1 to 2 days to prevent kernels and mycelium from clumping. When the fungus had spread throughout the jars, adequately colonizing the kernels with mycelium $(\approx 3$ to 4 weeks following inoculation), kernels were spread out on tarps to dry. Dry kernels were mixed together thoroughly prior to inoculating. Plots were inoculated in mid-November, 5 to 6 weeks after planting. At inoculation, $75 \mathrm{~g}$ of inoculum where scattered evenly by hand within each treated plot.

Puccinia triticina. Pots containing wheat plants infected with Puccinia triticina were transplanted into field plots to initiate leaf rust epidemics. In mid-March of both years, winter wheat cv. 
TAM 107 (10 seed per pot) was planted in $13.8-\mathrm{cm}^{2}$ Jiffy compressed peat pots (Jiffy Products of America, Inc., Batavia, IL) with Promix BX Mix soil (Premier Horticulture, St. Louis) in the greenhouse at 18 to $20^{\circ} \mathrm{C}$ under natural light. Plants were fertilized with Peter's 20-20-20 (Scotts-Sierra Horticultural Products Corp., Marysville, $\mathrm{OH}$ ) twice at 2-week intervals beginning 1 to 2 weeks after planting. Seedlings were inoculated two times to insure sufficient sporulation. $P$. triticina race MCDL was aerosol sprayed on 2-week-old seedlings with Soltrol light oil (Chevron Phillips Chemical Co. LP, Houston) as a carrier. This race is virulent on Jagger but not 2145. Following each inoculation, plants were put into a mist chamber at $12^{\circ} \mathrm{C}$ for at least $12 \mathrm{~h}$ in the dark, then returned to the previous greenhouse conditions. In midApril, two rust-infected pots were transplanted into the center of each treated field plot to allow rust infection to spread throughout the individual plots. In the second year of the study, transplants were watered manually one time immediately following planting at both sites due to drought conditions.

Disease sampling and ratings. Beginning when plants had reached the boot stage (Feekes 10.0) (25) during the first week of May or shortly thereafter, all plots were sampled for disease evaluations for a total of three times prior to maturity. In the first year, plots were sampled at three 2-week intervals. In the second year, disease was evaluated the first time at the boot stage, but virtually no disease symptoms were present, presumably due to drought conditions up to that time; therefore, the second sampling date was delayed for 3 weeks, followed by the third sampling date 1 week later. Within the six-row plots, sampling took place from the interior of rows two and five. Sample rows each were broken into five points from which the nearest tiller was harvested, for a total of 10 per plot: (i) one pace in from the edge $(\approx 0.5 \mathrm{~m})$, (ii) one pace from the first point, (iii) the very center of the row, (iv) one pace from the center, and (v) one pace from the fourth point (leaving one pace or $\approx 0.5 \mathrm{~m}$ from the edge). Ten tillers per plot (one per point per sample row) were sampled using this method at the first sampling date in both years. This was repeated at the second sampling date; in addition, two extra tillers of the minority cultivar were taken from plots with proportions of 0.25 and 0.75 Jagger from two different points (one per sampling row) randomly selected prior to sampling. At the third sampling date, 10 tillers per plot plus 4 extra tillers at random points were harvested: 4 extra from monoculture plots, 4 extra of the minority cultivar in plots with proportions of 0.25 and 0.75 , and 2 extra of each cultivar in plots with 0.50 proportions. Samples were taken to the laboratory and rated for tan spot and leaf rust severity. Plants were preserved in plastic bags at $4{ }^{\circ} \mathrm{C}$ for up to 10 days until they could be evaluated.

All four upper leaves on reproductive tillers were rated for tan spot and leaf rust severity at the first sampling date; however, because the cultivars had not headed out, they could not yet be distinguished in either year. Cultivars could be distinguished and were identified at the second (Feekes stage $\approx 10.54$ ) and third (Feekes stage $\approx 11.2$ ) sampling dates. The bottom leaf (flag-3) had senesced and often was missing in the second sampling and was discarded for the disease ratings. By the third sampling date, only the flag leaf (first year) or the flag plus flag-1 leaves (second year) had green leaf area; thus, disease ratings were limited to this leaf or leaves for all plants in that year. At the third sampling date, tan spot could not be rated accurately on Jagger due to moderate to severe rust symptoms rendering visual distinction of tan spot severity impossible. Tan spot severity was rated as percentage of leaf area visibly affected by the disease, ranging from 0 to $100 \%$. Leaf rust severity was rated using Cobb's scale (34).

Yield estimates. When plants were fully mature, $0.5-\mathrm{m}$ samples were harvested $1.0 \mathrm{~m}$ downwind from the center of each plot within each of the two innermost rows (wind direction was consistent at each field location). Tillers from these subplots were separated by cultivar based on chaff color, counted, and threshed.
Tiller number was counted and seed per subplot per cultivar was weighed and expressed in grams per tiller. Whole plots also were harvested and measured in terms of raw weight $(\mathrm{Mg} / \mathrm{ha})$ and thousand-kernel weight (TKW) in units of grams per 1,000 seed. A hailstorm at Hutchinson in 2002 just prior to harvesting caused high rates of shattering; thus, yield data were not available for this site-year.

Data analysis. To determine how disease severity changed as a function of the proportion of the susceptible cultivar within the wheat populations, we performed linear contrasts within an analysis of variance using the statistical programming package SAS (SAS Institute Inc., Cary, NC). For each disease, we estimated the linear, quadratic, and cubic parts of the curve describing the relationship between disease severity and the proportion of the susceptible cultivar. Values of all rated leaves were averaged within a plot for disease analyses. We evaluated leaf rust severity as a function of the proportion of the susceptible Jagger, and similarly evaluated tan spot severity as a function of the proportion of the susceptible 2145 per plot. For these analyses, we used both inoculated disease treatments that included the relevant pathogen in 2001 when ambient leaf rust and tan spot levels were relatively low; in 2002, because ambient rust and tan spot levels at both sites were comparable to inoculated levels, ambient and inoculated disease treatments were combined in the analyses. Ambient-diseased plots were analyzed separately in 2001. These analyses were performed both for separate site-years and for sites combined within a year, and focused primarily on data from the third sampling date when both diseases exhibited highest severities. Disease data from the first sampling date were not analyzed because cultivars could not be distinguished and severities of both diseases at all site-years were low or negligible. Residuals from the analyses were approximately normally distributed with equal variances and met the assumptions of the analysis of variance.

The second step in the analysis of disease severity was to compare the linear responses of the two different diseases to the proportion of susceptible genotype in mixture $(11,15)$. For each experimental unit (plot), we estimated the difference between the slopes of the curves for the two diseases using data from the third sampling date. Before calculating the difference, the slope for each disease was standardized within a plot by setting the severity on the susceptible cultivar in monoculture equal to one and scaling the severity in mixtures proportionately. An analysis of variance was performed on the set of estimated differences in slope to determine whether there was evidence that decreasing the proportion of the susceptible cultivar had a different effect on one disease compared with the other.

Yield analyses included fungicide-treated (i.e., nondiseased) plots in addition to the diseased plots, so that yield could be evaluated in both the absence and presence of disease. Ambient levels of both diseases were present in all plots except fungicidetreated plots; therefore, separate analyses for each inoculated and ambient disease treatment were not performed. Yield estimates were not available from Hutchinson in 2002; therefore, we had yield estimates for a total of three site-years. We analyzed yield in terms of both individual cultivar yield from the $1.0-\mathrm{m}^{2}$ subplots and total plot yield and TKW. For individual cultivar yield, linear contrasts, as in the analysis of disease severity, were used to determine the relationship between the proportion of the susceptible cultivar present and the yield of that cultivar in terms of seed weight and tiller number within the plot. For analyses of whole plot yield and TKW, the response in each mixture was compared with the appropriately weighted mean of responses in monocultures using linear contrasts in an analysis of variance.

\section{RESULTS}

Disease development. In all site-years of the experiment, disease levels of tan spot and leaf rust in inoculated plots at the time 
of the first sampling date in early May were low or negligible across all treatments. In 2001 at the second sampling date in midMay, both diseases were active at both sites. By the third sampling date in late May, both diseases reached high severities on susceptible plants (Table 1; Fig. 1A and B). During the same year, leaf rust severity was higher and tan spot severity was lower at Manhattan compared with Hutchinson by the third sampling date (Table 1). Greater amounts of ambient tan spot inoculum were present at Hutchinson relative to Manhattan, whereas ambient leaf rust inoculum was comparable at both sites (Table 1). Ambi- ent-diseased plots generally were less diseased than inoculated plots in 2001, though considerable levels of naturally occurring leaf rust and tan spot were present by the third sampling date for all site-years (Table 1). Fungicide-treated plots were virtually free of foliar disease symptoms for all site-years (data not shown).

In 2002 at the second sampling date in mid-May, both diseases were active at both sites. By the third sampling date in late May, both diseases reached high severities on susceptible plants, though both generally were lower compared with the first year (Table 1; Fig. 1C and D). Substantially higher severities of leaf

TABLE 1. Mean severities of leaf rust and tan spot on wheat cultivars Jagger (leaf rust susceptible) and 2145 (tan spot susceptible) within monocultures at the final sampling date of the season

\begin{tabular}{|c|c|c|c|c|c|c|c|c|}
\hline \multirow[b]{2}{*}{ Site } & \multicolumn{4}{|c|}{$2001^{a}$} & \multicolumn{4}{|c|}{$2002^{\mathrm{a}}$} \\
\hline & Tan spot ${ }^{\mathrm{b}}$ & Ambient tan spot ${ }^{\mathrm{c}}$ & Leaf rust ${ }^{\mathrm{d}}$ & Ambient leaf rust $\mathrm{e}^{\mathrm{e}}$ & Tan spot ${ }^{b}$ & Ambient tan spot ${ }^{\mathrm{c}}$ & Leaf rust $^{\mathrm{d}}$ & Ambient leaf rust \\
\hline Manhattan & $51.5(3.8)$ & $19.9(2.2)$ & $38.3(2.2)$ & $20.6(2.4)$ & $40.4(3.6)$ & $37.7(3.5)$ & $7.5(0.9)$ & $4.1(0.5)$ \\
\hline Hutchinson & $86.3(2.7)$ & $56.8(3.8)$ & $31.5(2.4)$ & $17.6(2.2)$ & $46.4(4.2)$ & $37.9(3.7)$ & $22.1(1.8)$ & $26.7(1.8)$ \\
\hline
\end{tabular}

a Values in parentheses are standard errors.

b Values are mean severities of tan spot on 2145 within inoculated monocultures. Tan spot severity was estimated as percent leaf area affected.

c Values are mean severities of tan spot on 2145 within ambient-diseased monocultures.

d Values are mean severities of leaf rust on Jagger within inoculated monocultures. Leaf rust severity was estimated using Cobb's scale.

e Values are mean severities of leaf rust on Jagger within ambient-diseased monocultures.

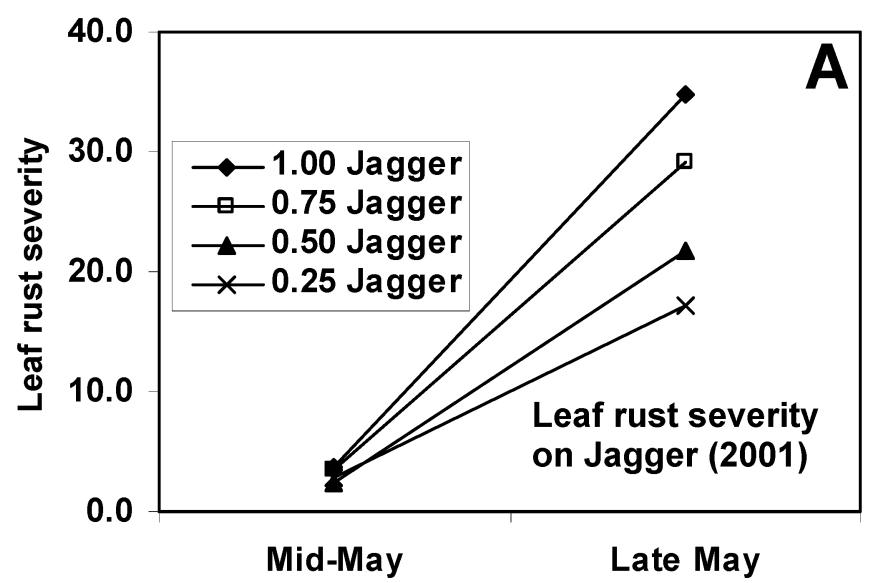

Sampling Date
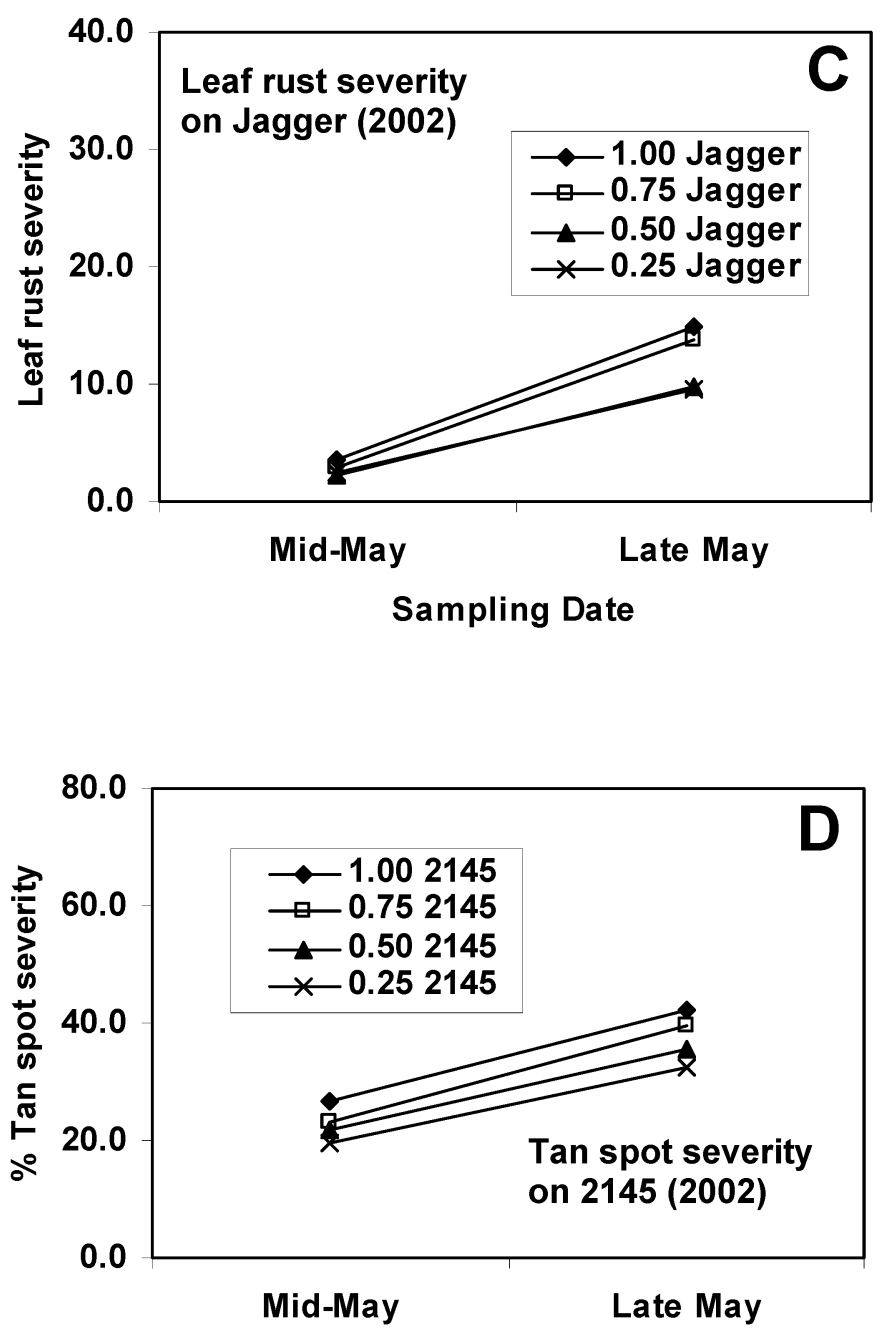

Sampling Date

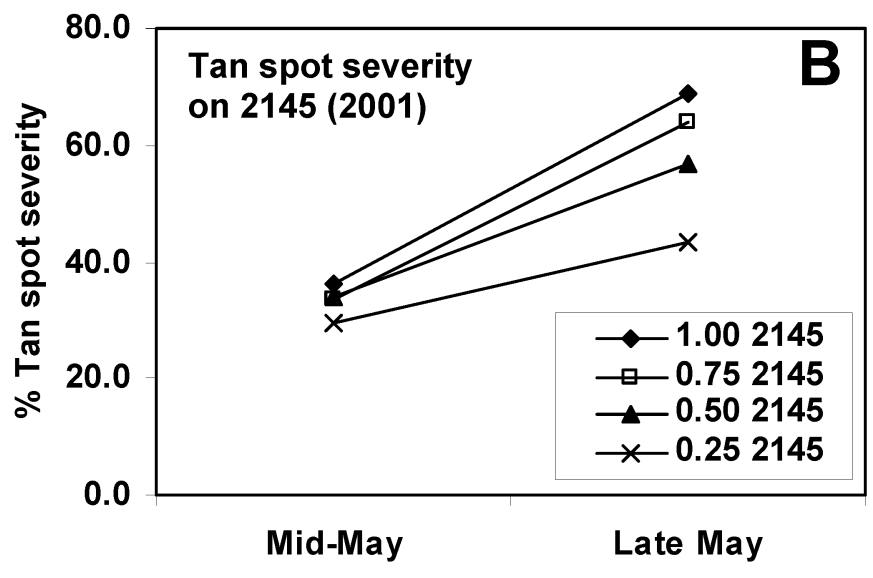

Sampling date

Fig. 1. Leaf rust and tan spot severity on susceptible wheat cvs. Jagger and 2145 in mixtures over time. Severity is reported for each disease as a function of proportion of the susceptible cultivar at the second sampling date in mid-May and the final sampling date during the last week of May. Leaf rust severity was estimated on Jagger using Cobb's scale. Tan spot severity was estimated on 2145 as percent leaf area affected. Means combine sites and treatments inoculated with both tan spot and leaf rust and either leaf rust alone (Jagger) or tan spot (2145) alone. A, Leaf rust progression on Jagger in 2001. B, Tan spot progression on 2145 in 2001. C, Leaf rust progression on Jagger in 2002. D, Tan spot progression on 2145 in 2002. 
rust occurred at Hutchinson than Manhattan due to a late-season arrival of ambient rust inoculum (Table 1). Tan spot and leaf rust severities were comparable at both sites in 2002 in both inoculated and ambient plots (Table 1).

Mixture effects on disease progression in 2001. For 2001 data, treatments inoculated with both diseases concurrently were combined with treatments inoculated with either leaf rust (Jagger) or tan spot (2145) alone, for disease analyses. There was a sitetreatment interaction, but the direction and significance of effects were the same when sites were analyzed individually. Severity differences between cultivar proportions grew larger over the growing season as disease progressed (Fig. 1A and B). By the third sampling date in late May, when both diseases were most severe, the highest and lowest leaf rust severities occurred on Jagger (susceptible) in monocultures and in 0.25 Jagger mixtures, respectively (Fig. 1A). Similarly, tan spot was most severe on 2145 (susceptible) in monocultures and lowest in 0.252145 mixtures (Fig. 1B).

Leaf rust severity on Jagger significantly decreased as the proportion of that cultivar decreased in mixtures at the second $(P<$ 0.0001 for linear, $P=0.1$ for quadratic, and $P=0.008$ for cubic components; data not shown) and third $(P<0.0001$ for linear, $P=$ 0.3 for quadratic, and $P=0.1$ for cubic components; Fig. 2A) sampling dates in inoculated plots. Leaf rust severities on Jagger at the third sampling date were on average 14, 42, and $57 \%$ less in mixtures of $0.75,0.50$, and 0.25 Jagger, respectively, relative to Jagger in monocultures. Leaf rust severity on 2145 (resistant) was negligible in all plots (data not shown).

Tan spot severity on 2145 also significantly decreased as the proportion of that cultivar decreased in mixtures at the second $(P=0.0004$ for linear, $P=0.1$ for quadratic, and $P=0.9$ for cubic components; data not shown $)$ and third $(P<0.0001$ for linear, $P=0.06$ for quadratic, and $P=0.4$ for cubic components; Fig. 2A) sampling dates in inoculated plots. Severities of tan spot on 2145 at the third sampling date were, on average 7,17 , and $37 \%$ less in mixtures of $0.75,0.50$, and 0.252145 , respectively, relative to 2145 in monocultures. Tan spot severity on Jagger (moderately resistant) within inoculated plots at the second sampling date (for reasons previously stated, tan spot was not rated on Jagger at the third sampling date) did not exceed an average of $17 \%$ and both the quadratic $(P=0.003)$ and cubic $(P=0.03)$ portions of the curve were significant as Jagger decreased in proportion, but not the linear $(P=0.2)$; Jagger in 0.50 mixtures had the highest tan spot severity, followed by proportions of 0.25 , 0.75 , and 1.00 (data not shown).

Although generally less diseased than inoculated plots, the effects of mixtures on the relevant susceptible cultivar in ambient plots also were significant $(P<0.0001$ for linear and $P>0.1$ for quadratic and cubic components) and were similar to inoculated plots for both leaf rust and tan spot (data not shown).

Mixture effects on disease progression in 2002. In 2002, disease severity of both leaf rust and tan spot in inoculated plots was not substantially higher than in ambient-diseased plots (Table 1); therefore, data from inoculated and ambient plots were combined for disease analyses. Furthermore, due to substantial differences in environmental conditions between sites, data from Manhattan and Hutchinson were analyzed separately, but combined graphically for simplicity.

At the second sampling date in mid-May, mixture effects on disease were significant $(P<0.05$ for the linear component, $P<$ 0.05 for the quadratic in terms of leaf rust on Jagger at Hutchinson and Manhattan, and $P=0.04$ for the cubic in terms of tan spot on 2145 at Hutchinson) at both sites for each disease on the appropriate susceptible cultivar, but the largest severity differences between cultivar proportions occurred by the third sampling date (Fig. 1C and D). By the third sampling date in late May when both diseases were most severe, leaf rust and tan spot on the susceptible cultivar at both sites were highest in monocultures and lowest in 0.25 Jagger and 0.252145 mixtures, respectively (Fig. 1C and D). At both sites at the third sampling date, for both leaf rust and tan spot, disease severity decreased on the susceptible cultivar as the proportion of susceptible cultivar decreased $(P<0.05$ for linear, and $P>0.1$ for most quadratic and cubic components, except $P=0.006$ for the quadratic in terms of leaf rust on Jagger at Manhattan; Fig. 2B). When sites were combined, severity of leaf rust on Jagger decreased by an average of 6,34 , and $38 \%$ in $0.75,0.50$, and 0.25 Jagger mixtures, respectively, relative to Jagger in monocultures. Tan spot severity on 2145 decreased by 6,16 , and $23 \%$ in $0.75,0.50$, and 0.252145 mixtures, respectively, relative to 2145 in monocultures. Leaf rust severities were negligible on 2145 and tan spot was less common on Jagger relative to the first year of the experiment (data not shown).

Relative mixture effectiveness: leaf rust versus tan spot. To determine the relative effectiveness of mixtures for leaf rust versus tan spot, standardized slopes of the linear response of each disease to the decreasing proportion of the susceptible cultivar were compared. In 2001, mixtures more effectively reduced leaf rust than tan spot at Hutchinson $(P=0.02)$ and Manhattan $(P=$ 0.08). When sites were combined in the analysis, $P=0.004$. In 2002, mixtures also had a significantly greater effect on leaf rust relative to tan spot at Manhattan $(P=0.002)$, but not at Hutchinson $(P=0.8)$; however, when sites were combined in the analysis,
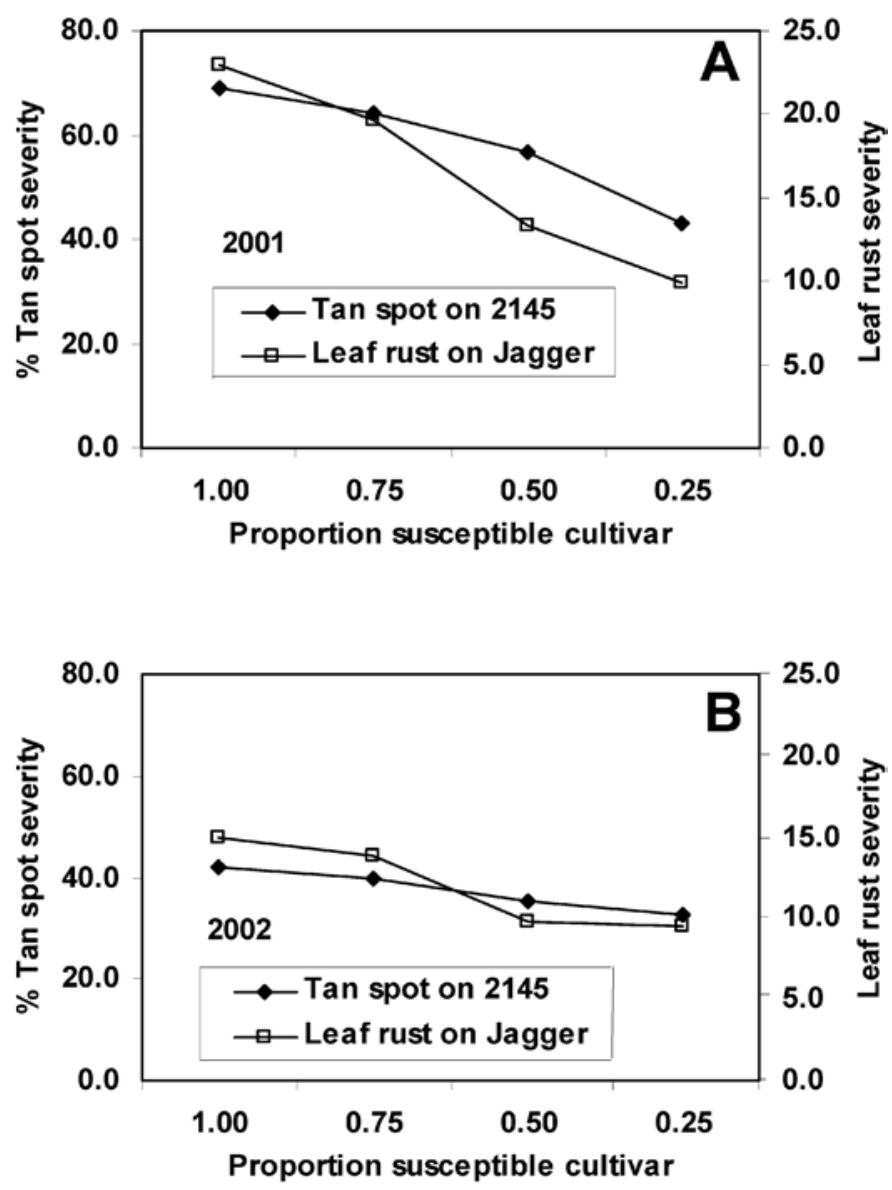

Fig. 2. Mean severities of leaf rust and tan spot on susceptible wheat cvs. Jagger and 2145 as a function of proportion of the susceptible cultivar. Values are from the final sampling date during the last week of May. Leaf rust severity was estimated on Jagger using Cobb's scale. Tan spot severity was estimated on 2145 as percent leaf area affected. Severity of each disease significantly $(P<0.05)$ decreased with decreasing proportion of the susceptible cultivar for each year. A, 2001 data. Means combine sites and treatments inoculated with both tan spot and leaf rust and either leaf rust alone (Jagger) or tan spot alone (2145). B, 2002 data. Means combine sites and all inoculated treatments plus the ambient treatment. 
$P=0.03$. In an analysis across all sites and years, the effectiveness of mixing wheat cultivars was greater for reducing the severity of leaf rust compared with tan spot at $P<0.0001$ (Fig. 3).

Mixture effects on yields at the whole-plot level. To determine mixture effects on yield at the whole-plot level, both TKW and raw weight $(\mathrm{Mg} / \mathrm{ha})$ were analyzed separately for nondiseased plots (fungicide-treated plots) and diseased plots (combining both inoculated and ambient treatments) for each mixture (Table 2).

Nondiseased plots. In fungicide-treated plots, 0.50 Jagger mixtures yielded higher $(P=0.09)$ raw weight at Manhattan in 2001 relative to expected values based on monocultures. At the same site-year and treatment level, both 0.50 and 0.75 Jagger mixtures yielded significantly $(P<0.05)$ higher TKW, and 0.25 Jagger mixtures also yielded higher $(P=0.09)$ TKW in the same year at Hutchinson. There were no significant differences between raw weights for fungicide-treated plots at Hutchinson in $2001(P>$ $0.1)$, or for either yield components at Manhattan in $2002(P>$ 0.1 ) at the same treatment level.

Diseased plots. In diseased plots, 0.25 Jagger mixtures yielded significantly $(P=0.02)$ higher TKW at Hutchinson in 2001 relative to expected values based on monocultures; all other yield

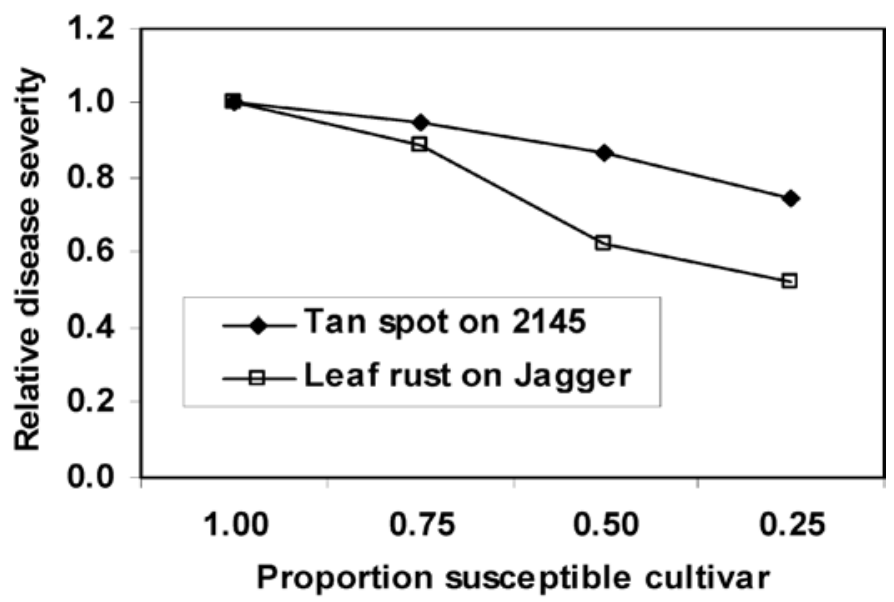

Fig. 3. Relative effects of mixtures for leaf rust versus tan spot on susceptible wheat cvs. Jagger and 2145. Values are from the final sampling date during the last week of May. Means combine site-years and treatments inoculated with both leaf rust and tan spot or either leaf rust alone (Jagger) or tan spot alone (2145) and combine all site-years. Relative severity of each mixture is expressed as a proportion of the severity in the susceptible monoculture. Leaf rust severity was estimated on Jagger using Cobb's scale. Tan spot severity was estimated on 2145 as percent leaf area affected. The two slopes are significantly $(P<0.0001)$ different. measurements were not significantly $(P>0.1)$ different between plots for that year. In 2002, 0.25 Jagger mixtures yielded higher $(P=0.07)$ raw weight than monocultures, and 0.50 Jagger mixtures actually yielded slightly lower $(P=0.06) \mathrm{TKW}$. There were no significant $(P>0.1)$ differences between diseased plots in terms of raw weight at Hutchinson in 2001, or for either yield measurement at Manhattan in 2001.

In summary, nondiseased mixtures yielded either higher raw weight or TKW than expected values in two of three site-years. Diseased mixtures yielded either more raw weight or TKW than expected values in two of three site-years; although, in one case at Manhattan in 2002, 0.50 Jagger mixtures yielded lower than other plots.

When site-years were combined in the analysis, 0.25 Jagger mixtures in diseased plots yielded higher $(P=0.08)$ raw weights and 0.75 Jagger mixtures in nondiseased plots yielded higher $(P=$ $0.03) \mathrm{TKW}$.

Mixture effects on yields of individual cultivars. To determine mixture effects on yield at the cultivar level, the number of tillers per square-meter subplots and grams per tiller per cultivar were analyzed separately for nondiseased plots (fungicide-treated plots) and diseased plots (combining both inoculated and ambient treatments) for each mixture (Table 3). Because tiller number always had a significant linear relationship with decreasing cultivar proportion, as expected, only the quadratic and cubic portions of the curve are discussed.

Nondiseased plots. In fungicide-treated plots, the number of Jagger tillers was higher than expected at Manhattan in 2002, and there was a significant $(P=0.04)$ quadratic relationship between yield and decreasing proportions of Jagger. The number of 2145 tillers was lower than expected at the same site-year, and both the quadratic $(P<0.0001)$ and cubic $(P=0.002)$ portions were significant. Jagger seed in 0.50 Jagger plots at Manhattan in 2001 yielded higher than in other proportions and there was a significant linear $(P=0.004)$ and quadratic $(P=0.04)$ relationship between yield and decreasing proportions of Jagger. Seed yield of 2145 significantly $(P<0.05)$ decreased as its proportion decreased in plots at Manhattan in 2001 and 2002.

Diseased plots. There was a significant $(P=0.005)$ quadratic relationship between increasing tiller number yields and decreasing proportions of Jagger at Hutchinson in 2001. The number of 2145 tillers was lower than expected at Manhattan in 2002, and both the quadratic $(P<0.0001)$ and cubic $(P<0.0001)$ portions were significant. There were significant linear $(P<0.0001)$ and quadratic $(P=0.0002)$ relationships between increasing seed yield and decreasing proportions of Jagger at Hutchinson in 2001; Jagger in 0.25 Jagger plots yielded the highest, followed by 0.50 , 0.75 , and monoculture Jagger plots, respectively. There were sig-

TABLE 2. Wheat yield and thousand kernel weight (TKW) at the whole-plot level as a function of proportion in nondiseased plots and plots diseased with leaf rust, tan spot, or both ${ }^{\mathrm{a}}$

\begin{tabular}{|c|c|c|c|c|c|c|c|c|c|c|c|}
\hline \multirow[b]{3}{*}{ Year, site } & \multirow[b]{3}{*}{ Yield } & \multicolumn{10}{|c|}{ Proportion of Jagger } \\
\hline & & \multicolumn{5}{|c|}{ Diseased plots ${ }^{\mathrm{b}}$} & \multicolumn{5}{|c|}{ Nondiseased plots ${ }^{\mathrm{c}}$} \\
\hline & & 0.00 & 0.25 & 0.50 & 0.75 & 1.00 & 0.00 & 0.25 & 0.50 & 0.75 & 1.00 \\
\hline \multicolumn{12}{|l|}{2001} \\
\hline Manhattan & $\mathrm{Mg} / \mathrm{ha}$ & 2.78 & 2.92 & 2.93 & 2.80 & 2.79 & 3.67 & 3.67 & $3.95^{*}$ & 3.68 & 3.60 \\
\hline \multirow[t]{2}{*}{ Hutchinson } & TKW & 26.3 & $27.7 * *$ & 27.6 & 27.3 & 28.0 & 30.2 & $31.4 *$ & 30.5 & 31.0 & 29.9 \\
\hline & $\mathrm{Mg} / \mathrm{ha}$ & 3.01 & 3.07 & 3.00 & 3.06 & 2.94 & 4.26 & 4.23 & 4.15 & 4.00 & 3.73 \\
\hline Manhattan & $\mathrm{Mg} / \mathrm{ha}$ & 3.89 & $3.86^{*}$ & 3.36 & 3.14 & 2.99 & 3.99 & 4.00 & 3.34 & 3.60 & 3.11 \\
\hline
\end{tabular}

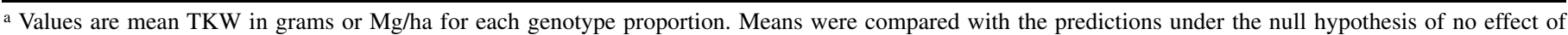
mixing. Null values were calculated as weighted means based on 2145 and Jagger monocultures (e.g., expected mean of a 0.75 Jagger mixture is the sum of the observed mean of Jagger monoculture multiplied by 0.75 and the observed mean of 2145 monoculture multiplied by 0.25 ). Asterisks following a value refer to a significant difference from the expected means at $\alpha=0.1\left(^{*}\right)$ and $0.05(* *) ;-$ refers to a lower than expected value.

$\mathrm{b}$ Values combine all disease treatments including inoculated and ambient plots.

c Values are from fungicide-treated plots only. 
nificant $(P \leq 0.004)$ negative linear relationships between seed yield of 2145 and decreasing proportion of 2145 at all site-years in diseased plots, including a significant $(P=0.01)$ quadratic relationship at Manhattan in 2002.

In summary, 2145 in nondiseased plots yielded slightly but significantly lower seed or tiller number in mixtures compared with monocultures in two of three site-years and in all site-years in diseased plots. Jagger, in contrast, typically yielded slightly higher seed or tiller number in mixtures, but this pattern was significant in only two cases in nondiseased plots and one case in diseased plots out of three site-years.

\section{DISCUSSION}

The severity of both tan spot and leaf rust was lower in mixtures relative to monocultures, whether the diseases occurred simultaneously or alone, for all site-years of the experiment. For both diseases, disease severity on the susceptible cultivar decreased as its proportion decreased in mixture. The results for leaf rust are consistent with a previous study in which mean leaf rust reductions of $32 \%$ were observed in 50:50 mixtures relative to monocultures of the component cultivars (26), although greater reductions were observed in the first year of the present study. As predicted based on life histories (14), mixtures were significantly more effective at reducing leaf rust relative to tan spot in three of four site-years.

Mixtures did not consistently yield greater than their expected weighted means, in spite of reduced disease and apparent disease effects on yield. It has been observed that the interaction between plant genotypes adds complexity and unpredictability to the relationship between disease severity and yield of a mixture (12). Jagger generally increased in yield when present in lower proportion, while 2145 decreased, though these trends were slight and, in many cases, were not statistically significant. Jagger yields did not always increase enough in mixture so that the total relative yields rose above 1.0. Although this study was not designed to test competition between these two cultivars, Jagger presumably is more competitive than 2145 because of its taller stature; thus, 2145 appears to be negatively affected when mixed with Jagger. In addition, the shape of the yield versus disease severity curve may be important. For example, if the curve is concave, rather than straight or convex, a partial reduction in disease severity does not produce a large yield benefit. It also is possible that the size of the treatment plots was too small to accurately judge mix- ture performance on yield. Mixture efficacy, particularly in terms of yield benefits, tends to be greater under production-scale deployment than in small-scale experimental plots $(17,30,45,46)$.

Growing mixtures may be desirable for reasons other than immediate yield benefits. For example, mixtures may have the potential to reduce residue-borne inoculum levels of Pyrenophora tritici-repentis over several seasons when deployed on a large scale (39). Mixing different genotypes also may be effective for the deployment and sustainability of major resistance genes, especially those vulnerable to "boom-and-bust" cycles (e.g., leaf rust) (28). Mixtures generally have been correlated with increased yield stability $(4,33,35,40)$ and, in fact, growers often are more interested in yield stability than in small yield increases associated with mixtures (32).

Determining the necessary level of composition complexity and number of components in a cultivar mixture for effectively reducing disease is a complex task. Small increases in host diversity within annual wheat populations, such as two-cultivar mixtures where one cultivar is resistant to a disease, can substantially reduce disease, as demonstrated in the present study. However, it is possible that the simplicity of the mixture may partially explain why yield benefits were not observed for several combinations.

Because of the aforementioned characteristics of tan spot (relatively few cycles, splash-dispersed, steep dispersal gradient, limited cultivar specificity), one might predict that mixtures of small grains would have little impact on disease progression. The results from the current study, however, show promise for mixtures to function in simultaneous disease control for both tan spot and leaf rust, though mixture efficacy was greater for leaf rust compared with tan spot. Although there is little doubt that mixtures of small grains can reduce severities of polycyclic, windborne, hostspecific foliar diseases (e.g., leaf rust) substantially, their effectiveness against residue-borne and soilborne diseases remains unpredictable and results in the literature are inconsistent. Some of the mechanisms proposed for reduced disease severity caused by polycyclic foliar pathogens in a gene-for-gene host interaction include dilution of inoculum due to the wider spatial distance between susceptible genotypes $(7,8,45)$, induced resistance $(24)$, and compensation by the resistant cultivar through increased tiller number (13). The mechanisms for disease reductions in soil- and residue-borne pathosystems are less understood $(32,33)$.

Induced resistance occurs when spores of an avirulent pathogen land on a resistant host and elicit a resistance mechanism that is

TABLE 3. Yield of individual wheat cultivars Jagger and 2145 as a function of proportion in nondiseased plots and plots diseased with leaf rust (Jagger), tan spot (2145), or both ${ }^{\mathrm{a}}$

\begin{tabular}{|c|c|c|c|c|c|c|c|c|c|c|}
\hline \multirow[b]{3}{*}{ Year, site } & \multirow[b]{3}{*}{ Cultivar } & \multirow[b]{3}{*}{ Yield } & \multicolumn{8}{|c|}{ Proportion of cultivar } \\
\hline & & & \multicolumn{4}{|c|}{ Diseased plots ${ }^{\mathrm{b}}$} & \multicolumn{4}{|c|}{ Nondiseased plots ${ }^{\mathrm{c}}$} \\
\hline & & & 0.25 & 0.50 & 0.75 & 1.00 & 0.25 & 0.50 & 0.75 & 1.00 \\
\hline \multicolumn{11}{|l|}{2001} \\
\hline \multirow[t]{4}{*}{ Manhattan } & Jagger & $\mathrm{g} /$ tiller & 0.83 & 0.82 & 0.78 & 0.76 & $0.93 *(2)$ & $0.98 *(2)$ & $0.94 *(2)$ & $0.93 *(2)$ \\
\hline & & tillers $/ \mathrm{m}^{2}$ & 38.3 & 63.6 & 95.7 & 119.1 & 37.0 & 69.4 & 94.2 & 123.6 \\
\hline & 2145 & $\mathrm{~g} /$ tiller & $0.57 *$ & $0.58 *$ & $0.62 *$ & $0.63 *$ & $0.60 *$ & $0.66^{*}$ & $0.67 *$ & $0.72 *$ \\
\hline & & tillers $/ \mathrm{m}^{2}$ & 28.1 & 59.3 & 90.3 & 130.2 & 31.8 & 59.2 & 96.2 & 130.8 \\
\hline \multirow[t]{4}{*}{ Hutchinson } & Jagger & $\mathrm{g} /$ tiller & $0.94 *(2)$ & $0.84 *(2)$ & $0.79 *(2)$ & $0.83 *(2)$ & 1.04 & 1.00 & 1.01 & 1.01 \\
\hline & & tillers $/ \mathrm{m}^{2}$ & $46.5(2)$ & $81.1(2)$ & $110.5(2)$ & $129.2(2)$ & 37.0 & 69.8 & 104.8 & 134.5 \\
\hline & 2145 & $\mathrm{~g} /$ tiller & $0.53 *$ & $0.58 *$ & $0.60^{*}$ & $0.70^{*}$ & 0.73 & 0.72 & 0.74 & 0.78 \\
\hline & & tillers $/ \mathrm{m}^{2}$ & 29.1 & 63.5 & 97.3 & 142.8 & 26.8 & 73.2 & 118.3 & 153.3 \\
\hline \multicolumn{11}{|l|}{2002} \\
\hline \multirow[t]{4}{*}{ Manhattan } & Jagger & $\mathrm{g} /$ tiller & 0.59 & 0.60 & 0.56 & 0.58 & 0.61 & 0.62 & 0.63 & 0.55 \\
\hline & & tillers $/ \mathrm{m}^{2}$ & 40.8 & 68.1 & 104.6 & 141.4 & $45.8(2)$ & $66.2(2)$ & $92.2(2)$ & $145.4(2)$ \\
\hline & 2145 & $\mathrm{~g} /$ tiller & $0.49 *(2)$ & $0.57 *(2)$ & $0.61 *(2)$ & $0.57 *(2)$ & $0.53^{*}$ & $0.57^{*}$ & $0.61 *$ & $0.68^{*}$ \\
\hline & & tillers $/ \mathrm{m}^{2}$ & $38.2(2,3)$ & $78.9(2,3)$ & $113.4(2,3)$ & $157.8(2,3)$ & $43.6(2,3)$ & $71.2(2,3)$ & $106.0(2,3)$ & $146.3(2,3)$ \\
\hline
\end{tabular}

${ }^{a}$ Values are mean $\mathrm{g} /$ tiller or tillers $/ \mathrm{m}^{2}$ for each individual cultivar within each proportion. An asterisk following a set of values refers to a significant linear relationship with decreasing proportion for that cultivar in the location-year indicated; 2 and 3 in parentheses refer to a significant quadratic and cubic relationship, respectively. $P<0.05$ for all significant values. Note: the significance of the linear portion of the curve for tillers $/ \mathrm{m}^{2}$ is not indicated by an asterisk.

${ }^{\mathrm{b}}$ Values combine all disease treatments including inoculated and ambient plots.

c Values are from fungicide-treated plots only. 
effective against virulent spores of a pathogen. Resistance induced by avirulent spores may contribute significantly to disease reductions in mixtures (24). Induced resistance has been observed, in particular, for rusts and powdery mildew of small grains such as leaf rust on wheat (42), in addition to saprophytic fungi on small grains (18). It is possible that induced resistance differs substantially between leaf rust and tan spot, which may have contributed to differences observed in mixture efficacy for the two diseases in addition to other differences in life histories. In a study of interactions between these two pathogens, sporulation by Puccinia triticina was reduced substantially by the presence of Pyrenophora tritici-repentis (1). In contrast, the presence of Puccinia triticina sometimes increased sporulation of Pyrenophora tritici-repentis (1).

The conduciveness of the environment may play a key role in mixture efficacy for reduced disease within a particular year and location. For example, Mundt et al. (33) generally failed to detect reductions in eyespot severities within wheat mixtures, contrary to Vilich-Meller (43), who reported substantial reductions of eyespot severity in mixtures of barley and wheat in Germany. Mundt et al. (33) hypothesized that the wetter environment in Germany relative to semi-arid eastern Oregon results in significant amounts of secondary spread of the pathogen, thereby increasing the efficacy of mixtures on eyespot severities. In the present study, the mechanisms responsible for reducing tan spot severities in the mixtures most likely are determined by the extent of the secondary spread of the pathogen. Central Kansas springs typically are wet and humid, creating a favorable environment for the spread of many pathogens, such as $P$. tritici-repentis, that benefit from these conditions. Environmental conditions during the first year of the present study were more conducive than the second year in terms of rainfall, temperature, and climate for both plant performance and disease progression, and probably represented an ideal year for mixture efficacy. During the second year, drought conditions and cold temperatures coupled with little snowfall created an environment in which both wheat and pathogens suffered for much of the growing season, and probably represented a worstcase scenario in terms of mixture efficacy.

In addition, mixtures may have a greater effect in older epidemics with overall high disease severity (32), provided the epidemic is not so severe that there is no time for an effect of mixtures to be realized $(16,45)$. Despite shorter epidemic durations (and presumably fewer generation cycles), generally lower disease severity, and large amounts of late-season leaf rust inoculum in the second year of the present study, disease trends in mixtures compared with monocultures were remarkably similar to the first year of the experiment, though disease reductions were smaller. Therefore, mixtures with the appropriate resistance functions would be expected to be effective against both leaf rust and tan spot and, presumably, other similar types of diseases in Kansas, under high and low disease pressures, and early and late disease infections. The results in this study, however, suggest that the greatest reductions in disease are likely to occur in more conducive years when infections are initiated early in the wheat-growing season and allowed to progress for relatively long durations.

In summary, functional mixtures with the appropriate resistance genes targeted against specific pathogen populations have the potential to simultaneously reduce severities of diseases incited by multiple pathogens with different life histories. A mixture of 2145 and Jagger effectively reduced the severities of both leaf rust and tan spot, two important wheat diseases in the Great Plains. As predicted, the effect of mixing generally was greater for leaf rust than for tan spot. Despite the fact that yield benefits due to mixing were modest and inconsistent, this system can be exploited as a model to predict the effectiveness of other, possibly more appropriate wheat cultivar mixtures, for the management of both wind- and residue-borne diseases in the Great Plains.

\section{ACKNOWLEDGMENTS}

This work was supported by a graduate fellowship from The Land Institute awarded to C. M. Cox, by the National Science Foundation under Grant No. DEB-0130692, by NSF Grant No. EPS-9874732 with matching support from the State of Kansas, by Regional Research Funds from North Central Project NC-125, and by the Kansas Wheat Commission. This is Kansas State Experiment Station Contribution No. 03-399-J. We thank W. W. Bockus and T. C. Todd for helpful comments on the manuscript; F. A. Al-Naimi for critical discussion of this work; and A. Berry, K. Galliher, C. Bylinowski, T. Setiyono, H. Ahmed, S. Jedlicka, J. Speier, A. Parks, E. Schraeder, and A. Raaf for their field assistance.

\section{LITERATURE CITED}

1. Al-Naimi, F. A. 2003. The Competitive Interaction between Pyrenophora tritici-repentis and Puccinia triticina. M.S. thesis. Kansas State University, Manhattan.

2. Bailey, K. L., and Duczek, L. J. 1996. Managing cereal diseases under reduced tillage. Can. J. Plant. Pathol. 18:159-167.

3. Bockus, W. W., and Claassen, M. M. 1992. Effects of crop rotation and residue management practices on severity of tan spot of winter wheat. Plant Dis. 76:633-636.

4. Bowden, R., Shroyer, J., Roozeboom, K., Claassen, M., Evans, P., Gordon, B., Heer, B., Janssen, K., Long, J., Martin, J., Schlegel, A., Sears, R., and Witt, M. 2001. Performance of wheat variety blends in Kansas. Kansas State Univ. Agric. Ext. Bull. 128.

5. Browning, J. A. 1974. Relevance of knowledge about natural ecosystems to development of pest management programs for agroecosystems. Pages 12-27 in: Proc. First Int. Wheat Genet. Symp. Manitoba, Canada.

6. Browning, J. A. 1988. Current thinking on the use of diversity to buffer small grains against high epidemic and variable foliar pathogens: Problems and future prospects. Pages 76-90 in: Breeding Strategies for Resistance to the Rusts of Wheat. N. W. Simmonds and S. Rajaram, eds. CIMMYT, Mexico, D.F.

7. Burdon, J. J., and Chilvers, G. A. 1977. Controlled environment experiments on epidemic rates of barley mildew in different mixtures of barley and wheat. Oecologia 28:141-146.

8. Chin, K. M., and Wolfe, M. S. 1984. Selection on Erysiphe graminis in pure and mixed stands of barley. Plant Pathol. 33:535-546.

9. Cowger, C., and Mundt, C. C. 2002. Effects of wheat cultivar mixtures on epidemic progression of Septoria tritici blotch and pathogenicity of Mycosphaerella graminicola. Phytopathology 92:617-623.

10. Eversmeyer, M. G., and Kramer, C. L. 2000. Epidemiology of wheat leaf and stem rust in the central Great Plains of the USA. Annu. Rev. Phytopathol. 38:491-513.

11. Feldman, H. A. 1988. Families of lines: Random effects in linear regression analysis. J. Appl. Physiol. 64:1721-1732.

12. Finckh, M. R., Gacek, E. S., Goyeau, H., Lannou, C., Merz, U., Mundt, C. C., Munk, L., Nadiak, J., Newton, A. C., de Vallavieille, P. C., and Wolfe, M. S. 2000. Cereal variety and species mixtures in practice. Agronomie 20:813-837.

13. Finckh, M. R., and Mundt, C. C. 1992. Plant competition and disease in genetically diverse wheat populations. Oecologia 91:81-92.

14. Garrett, K. A., and Mundt, C. C. 1999. Epidemiology in mixed host populations. Phytopathology 89:984-990.

15. Garrett, K. A., and Mundt, C. C. 2000. Effects of planting density and the composition of wheat cultivar mixtures on stripe rust: An analysis taking into account limits to the replication of controls. Phytopathology 90:1313-1321.

16. Garrett, K. A., Nelson, R. J., Mundt, C. C., Chacón, G., Jaramillo, R. E., and Forbes, G. A. 2001. The effects of host diversity and other management components on epidemics of potato late blight in the humid highland tropics. Phytopathology 91:993-1000.

17. Gieffers, W., and Hesselbach, J. 1988. Disease incidence and yield of different cereal cultivars in pure stand and mixtures. I. Spring barley (Hordeum vulgare L.) Z. Pflanzenkrankh. Pflanzenschutz 95:46-62.

18. Gregersen, P. L., and Smedegaard, V. 1989. Induction of resistance in barley against Erysiphe graminis f. sp. hordei after preinoculation with the saprophytic fungus, Cladosporium macrocarpum. J. Phytopathol. 124:128-136.

19. Halloin, J. M., and Johnson, D. J. 2000. Reduction of sugarbeet losses from Rhizoctonia crown and root rot by use of mixtures of resistant and susceptible varieties. (Abstr.) Phytopathology 90:S33.

20. Hariri, D., Fouchard, M., and Prud'homme, H. 2001. Incidence of soilborne wheat mosaic virus in mixtures of susceptible and resistant wheat cultivars. Eur. J. Plant Pathol. 107:625-631.

21. Krupinsky, J. M. 1982. Observations on the host range of isolates of Pyrenophora trichostoma. Can. J. Plant Pathol. 4:42-46. 
22. Krupinsky, J. M., and Tanaka, D. L. 2001. Leaf spot disease on winter wheat influenced by nitrogen, tillage, and haying after a grassalfalfa mixture in the Conversation Reserve Program. Plant Dis. 85:785789.

23. Lannou, C., de Vallavieille-Pope, C., Biass, C., and Goyeau, H. 1994. The efficacy of mixtures of susceptible and resistant hosts to two wheat rusts of different lesion size: controlled condition experiments and computerized simulations. J. Phytopathol. 140:227-237.

24. Lannou, C., de Vallavieille-Pope, C., and Goyeau, H. 1995. Induced resistance in host mixtures and its effects on disease control in computersimulated epidemics. Plant Pathol. 44:478-489.

25. Large, E. C. 1954. Growth stages in cereals. Illustration of the Feekes scale. Plant Pathol. 3:128-129.

26. Mahmood, T., Marshall, D., and McDaniel, M. E. 1991. Effect of winter wheat cultivar mixtures on leaf rust severity and grain yield. Phytopathology 81:470-474.

27. McDonald, B. A., Allard, R. W., and Webster, R. K. 1988. Responses of two-, three-, and four-component barley mixtures to a variable pathogen population. Crop Sci. 28:447-452.

28. McDonald, B. A., and Linde, C. 2002. Pathogen evolution genetics, evolutionary potential, and durable resistance. Annu. Rev. Phytopathol. 40:349-379.

29. Mitchell, C. E., Tilman, D., and Groth, J. V. 2002. Effects of grassland plant species diversity, abundance, and composition on foliar fungal disease. Ecology 83:1713-1726.

30. Mundt, C. C. 1994. Use of host genetic diversity to control cereal diseases: Implications for rice blast. Pages 293-307 in: Rice Blast Disease. S. Leong, R. S. Zeigler, and P. S. Teng, eds. CABI International, Cambridge.

31. Mundt, C. C. 2002. Performance of wheat cultivars and cultivar mixtures in the presence of Cephalosporium stripe. Crop Prot. 21:93-99.

32. Mundt, C. C. 2002. Use of multiline cultivars and cultivar mixtures for disease management. Annu. Rev. Phytopathol. 40:381-410.

33. Mundt, C. C., Brophy, L. S., and Schmitt, M. S. 1995. Disease severity and yield of pure-line wheat cultivars and mixtures in the presence of eyespot, yellow rust, and their combination. Plant Pathol. 44: $173-182$.
34. Peterson, R. F., Cambell, A. B., and Hannah, A. E. 1948. A diagrammatic scale for estimating rust intensity on leaves and stems of cereals. Can. J. Res. C 26:496-500.

35. Pfahler P. L., and Linskens, H. F. 1979. Yield stability and population diversity in oats (Avena spp.). Theor. Appl. Genet. 54:1-5.

36. Raymond, P. J., Bockus, W. W., and Norman, B. L. 1985. Tan spot of winter wheat: Procedures to determine host response. Phytopathology 75:686-690.

37. Schuh, W. 1990. The influence of tillage systems on incidence and spatial pattern of tan spot of wheat. Phytopathology 80:804-807.

38. Shabeer, A., and Bockus, W. W. 1988. Tan spot effects on yield and yield components relative to growth stage in winter wheat. Plant Dis. 72:559-602.

39. Shefelbine, P. A., and Bockus, W. W. 1989. Decline of Cephalosporium stripe by monoculture of moderately resistant winter wheat cultivars. Phytopathology 79:1127-1130.

40. Smithson, J. B., and Lenne, J. M. 1996. Varietal mixtures: a viable strategy for sustainable productivity in subsistence agriculture. Ann. Appl. Biol. 128:127-158.

41. Sone, J., Bockus, W. W., and Claassen, M. M. 1994. Gradients of tan spot of winter wheat from a small area source of Pyrenophora tritici-repentis. Plant Dis. 78:622-627.

42. Van Asch, M. A. J., Rijenberg, F. H. J., and Coutinho, T. A. 1992. Resistance induced in wheat by an avirulent race of Puccinia recondita $\mathrm{f}$. sp. tritici. Plant Dis. 76:412-415.

43. Vilich-Meller, V. 1992. Pseudocercosporella herpotrichoides, Fusarium spp. and Rhizoctonia cerealis stem rot in pure stands and interspecific mixtures of cereals. Crop Prot. 11:45-50.

44. Wiese, M. V. 1987. Compendium of Wheat Diseases. The American Phytopathological Society, St. Paul, MN.

45. Wolfe, M. S. 1985. The current status and prospects of multiline cultivars and variety mixtures for disease resistance. Annu. Rev. Phytopathol. 64:148-155.

46. Wolfe, M. S., and Barrett, J. A. 1980. Can we lead the pathogen astray? Plant Dis. 64:148-155

47. Zhu, Y., Hairu, C., Fan, J., Wang, Y., Li, Y, Chen, J., Fan, J, Yang, S., Hu, L., Leung, H., Mew, T. W., Teng, P. S., Wang, Z., and Mundt, C. C. 2000 Genetic diversity and disease control in rice. Nature 406:718-722. 